\title{
Thermodynamic characterisation of Dppc/Polylysine derivatives mixed monolayers
}

\author{
J. Remenyí ${ }^{1}$, F. Reig ${ }^{2}$, P. Sospedra ${ }^{3}$, A. Ortiz ${ }^{3}$ and F. Hudecz ${ }^{1}$ \\ ${ }^{1}$ Research Group for Peptide Chemistry, Hungarian Academy of Science, Ëotvös L. University, \\ PO. Box 32, 1518 Budapest 112, Hungary \\ 2 Peptides Department, Institut for Biological and Environmental Chemistry, Jordi Girona 18, \\ 08034 Barcelona, Spain \\ ${ }^{3}$ Physicochemical Department, Faculty Pharmacy, University Barcelona, Pza. Puis XII, \\ 08028 Barcelona, Spain
}

\begin{abstract}
Mixed monolayer of DPPC and a daunomycin-polylysine conjugate, based on a (poly[Lys-(DL$\left.\left.\mathrm{Ala}_{\mathrm{m}}-\mathrm{Glu}_{\mathrm{i}}\right)\right]$ (EAK) core with daunomycin molecules attached through the acid labile cis-aconytil moiety, were studied and thermodynamic parameters associated to this interaction calculated.

The same experiments were carried out in parallel with plain polymer and the results obtained indicate that the presence of Daunomycin attached to the lateral chains of polymer backbone modifies the overall surface characteristics of these derivatives.
\end{abstract}

\section{INTRODUCTION}

Peptides and proteins have already demostrated an use as targeting carriers of drugs, toxins, radionuclides, enzymes, oligonucleotides and genes. Synthetic macromolecules such as linear or branched chain poly- $\alpha$-amino acids, polydepsipeptides and peptide-spacer containing non-peptidic polymers have also been used as soluble drug conjugates for "passive targeting" resulting in altered pharmacokinetics (e.g. accumulation in tumour), decreased non-specific toxicity and immunogenicity [1]. To this end we have developed a new group of water-soluble drug-conjugates in which acid labile cis-aconytil derivative of daunomycin (cAD) is coupled to amphoteric branched polypeptide, (poly[Lys-(DL-Ala $\left.\left.\mathrm{m}_{\mathrm{m}}-\mathrm{Glu}_{\mathrm{i}}\right)\right](\mathrm{EAK})$ derived from polylysine. Anthracyclin antibiotics, like Daunomycin are widely used in cancer chemotherapy but side effects (e.g. immunosuppression, cardiotoxicity) and multidrug resistance developed during the treatment, seriously limit the therapeutic efficiency. Dau-EAK conjugate was very effective against L1210 leukaemia in vivo producing 66-100\% long-term survivors ( $>60$ days) in mice[2, 3].

In this report we present data on the interaction between amphoteric polypeptide (EAK) and its conjugate ( cAD-EAK) with phospholipids model membranes. 


\section{EXPERIMENTAL SECTION}

Polypeptide and cAD-polypeptide conjugate were prepared as described earlier [2]. The ability of these peptides to spread on aqueous surfaces and form stable monolayer was determined in a Langmuir film (Nima type 601A) using a rectangular Teflon cuvette (maximum area of $568 \mathrm{~cm}^{2}$ and $270 \mathrm{~cm}^{3}$ of capacity). Polylysine derivatives were first dissolved in DMSO and from these stock solutions, final forms were prepared $(1.36 \mathrm{mM})$ in chloroform and spread on a PBS buffer subphase $(\mathrm{pH}=7.4)$ using a microsyringe (Hamilton). After ten minutes, monolayers were compressed at a rate of $50 \mathrm{~cm} / \mathrm{min}$., up to collapse and surface pressure was continuously recorded during film compression. All experiments were carried out at room temperature $\left(25^{\circ} \mathrm{C}\right)$.

For the miscibility study different molar mixtures $(8: 2,6: 4,4: 6$, and $2: 8)$ of polylysine derivatives/DPPC dissolved in methanol were prepared. Compression isotherms of each sample as well as those of pure components were recorded applying $25 \mu \mathrm{l}$ of the corresponding solutions on the aqueous surface. The surface compression modulus, $\left(\mathrm{C}_{\mathrm{s}}^{-1}\right)$, was calculated applying Eq.1:

$$
\mathrm{C}_{\mathrm{s}}^{-1}=-\mathrm{A}(\partial \pi / \partial \mathrm{A})_{\mathrm{T}}
$$

where (A) is the molecular area of mixed film and $\pi$ the surface pressure.

To better visualize the miscibility between both components area/molecule values versus the molar composition of the mixtures were represented.

\section{RESULTS AND DISCUSSION}

The EAK conjugate with an amphoteric branched polypeptide can be considered as a neutral zwiterionic system. Further substitution at the $\alpha$ - amino group of glutamic acid by the carboxylic residues of cis-aconytil -daunomycin although at a small degree (4.1\%), modifies slightly the overall electrical charge of the conjugate rendering it a polyanion with a few and hindered negatively charged carboxyl groups.

Comparing surface pressure curves for cAD-EAK and EAK the shape and slope correspond in both samples to expanded monolayers, being the cAD-EAK isotherm the most expanded (Figure 1 and Figure 2). Maximum surface pressure compressions achieved were 17 and $18 \mathrm{mN} / \mathrm{m}$, respectively. Although the number of molecules spread were the same in all cases, cAD-EAK shows an initial pressure of $0.88 \mathrm{mN} / \mathrm{m}$ and a transition around $4-6 \mathrm{mN} / \mathrm{m}$ surface pressure.

Table 1. Values of area-residue obtained from the peptide compression isotherms.

\begin{tabular}{c|c|c|c}
\hline & $\begin{array}{c}\text { Area } \\
\text { Lift -off }\end{array}$ & $\begin{array}{c}\text { Area } \\
\text { Extrapolated }\end{array}$ & $\begin{array}{c}\text { Area } \\
\pi \text { max }\end{array}$ \\
\hline \hline EAK & $1.2 \mathrm{~nm}^{2}$ & $0.24 \mathrm{~nm}^{2}$ & $0.036 \mathrm{~nm}^{2}$ \\
\hline cAD-EAK & $2 \mathrm{~nm}^{2}$ & $0.45 \mathrm{~nm}^{2}$ & $0.082 \mathrm{~nm}^{2}$ \\
\hline
\end{tabular}


Compression isotherms corresponding to different conjugate/DPPC monolayer compositions are represented in Figure 1 and Figure 2. Mixed monolayers show intermediates values, between those of individual components, thus indicating a regular miscibility pattern of cAD-EAK and EAK with DPPC. The plots surface pressure $(\pi)$ /area residue of mixed compositions show the transition of liquid expanded to liquid condensed monolayers as the film is compressed, except for the film corresponding to 0.2 DPPC molar fraction, where DPPC transition around 8-10 mN/m surface pressure disappeared.

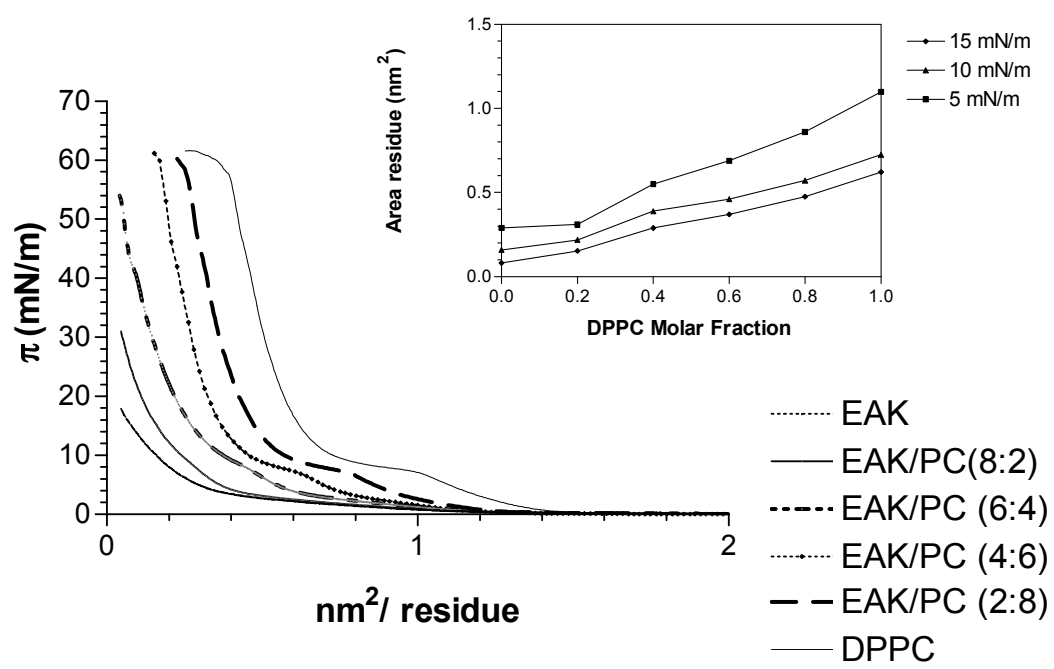

Figure 1. Compression isotherms of EAK/DPPC mixed monolayer of different molar compositions on PBS buffer. Inset displays mean residue area vs DPPC molar fraction at different surface pressure 5,10 and $15 \mathrm{mN} / \mathrm{m}$.

$\left(\mathrm{C}_{\mathrm{s}}^{-1)}\right.$ values can be used to characterize the phase state of a monolayer, according to [4]. For liquid expanded films this parameter ranges from 12.5 to $50 \mathrm{mN} / \mathrm{m}$, while for liquid-condensed phases, ranges from 100 to $250 \mathrm{mN} / \mathrm{m}^{-C_{\mathrm{s}}^{-1}}$ values calculated for cAD-EAK or EAK/DPPC mixtures are in the range of liquid condensed phase, like for pure DPPC, while pure cAD-EAK and EAK samples form liquid expanded films. The surface compression modulus is correlated with the series of plots surface pressure $v s$ residue molecular area obtained.

To better study the miscibility, the area/residue values versus peptide molar fraction were represented in the inset Figure 1 and Figure 2. In two components monolayer, the average area per molecule for an ideal mixed film is calculated from the contributions of both components.

The miscibility of EAK/DPPC and CAD-EAK/DPPC at pressures of 5, 10 and $15 \mathrm{mN} / \mathrm{m}$, are shown in the inset of the figures. Deviations from ideality are low and negative mainly at low pressures. Besides, at pressures of 10 or $15 \mathrm{mN} / \mathrm{m}$ miscibility is almost ideal. Nevertheless, deviations from ideality were quantified thorough calculation of free energy of mixing $\left(\Delta \mathrm{G}_{\mathrm{M}}{ }^{\mathrm{Ex}}\right)$, interaction parameter $(\alpha)$, and enthalpy $(\Delta \mathrm{H})$ as described in [5]. The thermodynamic parameters resulting from these equations applied to data corresponding to $10 \mathrm{mN} / \mathrm{m}$, are presented in Table 2 and Table 3. 


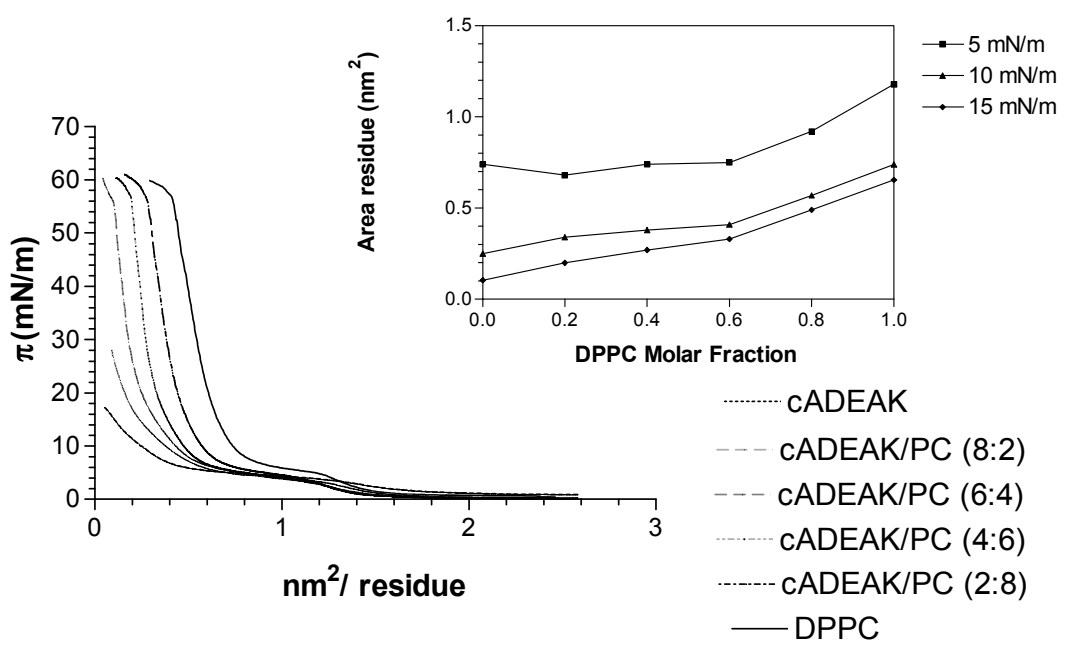

Figure 2. Compression isotherms of cAD-EAK/DPPC mixed monolayer of different molar fraction on PBS buffer. Inset displays mean residue area $v s$ DPPC molar fraction at different surface pressures 5,10 and $15 \mathrm{mN} / \mathrm{m}$

Table 2. Thermodynamic parameters for EAK/DPPC mixtures at $10 \mathrm{mN} / \mathrm{m}$ (subphase PBS).

\begin{tabular}{c|c|c|c}
\hline $\begin{array}{c}\text { DPPC } \\
(\mathrm{X})\end{array}$ & $\begin{array}{c}\Delta \mathrm{G}_{\mathrm{M}}^{\mathrm{Ex}} \\
(\mathrm{J} / \mathrm{mol})\end{array}$ & $\alpha$ & $\Delta \mathrm{H}(\mathrm{J} / \mathrm{mol})$ \\
\hline \hline DPPC 0.2 & -422.94 & -1.08 & ----- \\
\hline DPPC 0.4 & -226.71 & -0.39 & ----- \\
\hline DPPC 0.6 & -624.34 & -1.06 & -1300.7 \\
\hline DPPC 0.8 & -162.50 & -0.42 & -507.8 \\
\hline
\end{tabular}

Table 3. Thermodynamic parameters for cAD-EAK/DPPC mixtures at $10 \mathrm{mN} / \mathrm{m}$ (subphase PBS).

\begin{tabular}{c|c|c|c}
\hline $\begin{array}{c}\text { DPPC } \\
(\mathrm{X})\end{array}$ & $\begin{array}{c}\Delta \mathrm{G}_{\mathrm{M}}^{\mathrm{Ex}} \\
(\mathrm{J} / \mathrm{mol})\end{array}$ & $\alpha$ & $\Delta \mathrm{H}(\mathrm{J} / \mathrm{mol})$ \\
\hline \hline DPPC 0.2 & -1940.13 & -4.95 & ----- \\
\hline DPPC 0.4 & -636.87 & -1.09 & -1326.8 \\
\hline DPPC 0.6 & -697.82 & -1.19 & -1453.8 \\
\hline DPPC 0.8 & -559.42 & -1.44 & -1753.8 \\
\hline
\end{tabular}

The values of free energy of mixing $\left(\Delta \mathrm{G}_{\mathrm{M}}{ }^{\mathrm{Ex}}\right)$ are lower than RT $\left(2474 \mathrm{Jmol}^{-1}\right)$, for both polymeric structures, indicating that deviations from ideality are not significant. 


\section{CONCLUSIONS}

The cAD-EAK conjugate and the free EAK polypeptide studied are miscible with DPPC. Negative deviations versus ideality indicate the presence of attractive forces between the two types of molecules in the monolayer studied. These properties suggest a good association of these polymers with biological membranes.

\section{Acknowledgements}

Experimental work summarised in this paper was supported by grants from the Hungarian-Spanish Intergovernmental Programme (2/2003), from the Hungarian Research Fund (OTKA No. T-045679), from the Hungarian Ministry of Culture (Medichem NFKP 1/047) and from the ministry of Health (ETT 544/2003).

\section{References}

[1] Hudecz, F., In Agelli, A., Boden, N. and Zhang, S. (eds) Self-Assembling peptide systems in biology, medicine and engineering, Kluwer Academic Publisher, The Netherlands, 2001, p. 139.

[2] [2 ] Gaál, D. and Hudecz, F. Eur. J. Cancer, 34 (1998) 155.

[3] [3] Hudecz, F., Clegg, J.A., Kajtár, J., Embleton, M.J., Szekerke, M. and Baldwin, R.W. Bioconjugate Chem. 3 (1992) 49.

[4] [4] Davies, J.T. Rideal,E.K., Interfacial Phenomena, $2^{\text {nd }}$ ed. Academic press: NewYork and London 1963;pp265.

[5] [5] Almiñana, N., Alsina, M.A, Espina, M., Reig, F., J. Coll .Interf. Sci 263 (2003) 432-440. 